\title{
Stress, Executive Function, Resilience and Quality of Life in Portuguese Subjects in Situations of Economic Insufficiency and Unemployment
}

\author{
Eduardo Gonçalves ${ }^{1}$, Saul Neves de Jesus ${ }^{2}$ \\ ${ }^{1}$ Department of Psychiatry and Mental Health of Hospital Center of Algarve, Faro, Portugal \\ ${ }^{2}$ Department of Psychology of Faculty of Social and Human Sciences of University of Algarve, Faro, Portugal \\ Email: eduar.goncalves@gmail.com
}

Received 15 August 2015; accepted 12 October 2015; published 15 October 2015

Copyright (C) 2015 by authors and Scientific Research Publishing Inc.

This work is licensed under the Creative Commons Attribution International License (CC BY).

http://creativecommons.org/licenses/by/4.0/

\section{(c) (i) Open Access}

\begin{abstract}
The aim of this study is the investigation of the impact of stress of Portuguese subjects in situations of economic insufficiency and unemployment on executive function and quality of life and the coping strategies and resilience skills used. The sample consists of 41 participants. The psychometric instruments used are validated for Portuguese population, measure (perceived) stress, coping, material deprivation, resilience and quality of life, defined by World Health Organization. Executive function has been evaluated through performances at Stroop and Berg tasks. It has been concluded that, in this population, resilience skills and active coping strategies are positively correlated with quality of life. Quality of life is negatively correlated with material deprivation. Active coping strategies are supported by adequate executive function, which neurobiological substrate is dorso-lateral prefrontal cortex. Not active coping strategies correlate negatively with cognitive flexibility, suggesting the presence of a deficit at infero-lateral prefrontal cortex.
\end{abstract}

\section{Keywords}

Stress, Economic Insufficiency, Unemployment, Coping, Resilience, Quality of Life, Executive Function 


\section{Introduction (Theoretical Framework)}

\subsection{Stress, Coping, Emotion, Anxiety, Depression, Perceived Stress and Unifying (Heuristic) Model of Stress Process}

Lazarus and Folkman (1984) [1] define the psychological stress as "a particular relation between the person and his/her involvement appraised by the person as taxing or excessive in relation to his/her resources, endangering his/her well-being." On this evaluation, and according to these authors, "cognitive appraisal can be more easily understood as the process of categorizing the stress encounter, and its various facets, with respect to their importance to the well-being". They identify two main categories of appraisal: the primary appraisal, which is an evaluation of what is at stake in the stressful encounter; the secondary appraisal, which is an evaluation of options and resources to handle the stressful meeting. Also they emphasize three major potential outcomes of the primary appraisal, which provide an initial classification of the implications for the adaptation to person's circumstances: they can be appraised as irrelevant to his/her well-being, if they not relate to the needs and objectives of the person; they can be appraised as benign and positive, if they are evaluated as reassuring or incrementing the person's well-being; or they can be appraised as stressful if the needs and objectives of the person are implicated in the situation in a way that exceeds the personal resources, being these appraisals which result in a reaction to stress, that mobilize the person to respond to the situation, evoked by stress, through coping. Lazarus and Folkman (1984) [1] also identified three subtypes of stressful appraisals, from which run a more accurate categorization of the nature of the conditions evocative of stress: damage (and loss); threat; challenge. Damage appraisals reflect situations in which a person has suffered some kind of prejudice (whether through injury, illness, loss of self-esteem or some other type of setback in his/her objectives and activities). Threat appraisals focus on the existing potential in the situation related with future obtaining of damage (and loss). Challenge appraisals are focused on the existing potential in the situation related with future obtaining of gain. The difference between stress-related damage or threats, on the one hand, and stress-related challenge, in the other, is in concordance with the distinction, advanced by Selye (1974) [2], between negative stress or distress and positive stress or eustress. The evaluation of control potential, existing within the individual, on the stressful transaction person-involvement, is mentioned, as an important form of secondary appraisal, by Lazarus and Folkman (1984) [1], who observe that challenge appraisals, rather than threat ones, are especially likely when the person has a sense of personal control over the transaction. Individuals sustain as important motivational commitments, including goals and personal values, which are identified as relevant antecedents of their primary appraisals. As for the situation, and also according to these authors, many formal properties of events, including their novelty, predictability, uncertainty, eminence, duration and ambiguity have been identified as potentially important for appraisal. For Lazarus and Folkman (1984) [1], coping consists of "cognitive and behavioral efforts, constantly changing, to manage specific external and/or internal demands that are assessed as exceeding the resources of the person". Moreover, they differentiate two basic functions corresponding to two different types of coping. Folkman and Lazarus (1980) [3] argue that problem focused coping refers to the "management or change of the transaction person-involvement, which is the source of stress," while emotion focused coping refers to "the regulation of stressful emotions" that arise in response to the problem. They also propose that problem focused coping includes more intra-personal strategies that would reduce the problem through motivational and cognitive changes, such as changing aspiration's level, developing new behavioral patterns, reducing investment's degree in the situation. Emotion focused coping is described as consisting primarily of a series of cognitive processes in order to reduce emotional distress, including avoidance, minimization, reevaluation of the situation in a more positive way, without really changing it (Lazarus \& Folkman, 1984) [1]. Smith and Lazarus (1990) [4] argued that the knowledge of the emotional state of a person allows to gather more information about how that person is doing appraisals of his/her circumstances and the likelihood of behaving, than simply stating that the person is having a stressful experience. According to Lang (1995) [5], human experience can be characterized by two dimensions: valence and arousal (neuro-physiological activation). Valence refers to an evaluation continuum, that ranges from a state of displeasure (negative/unpleasant) to a state of pleasure (positive/pleasant), and arousal refers to an evaluation continuum that ranges from a state of calm to a state of maximum activation (excitation state of alert). While valence response guides the behavior by activating the motivational system (approach/appetitive behavior versus avoidance, withdrawal/aversive behavior), arousal corresponds to the magnitude of this response [5]. Negative emotions, in association with passive arousal, correspond to emotional/affec- 
tive states of sadness, resignation, and, with greater intensity, to states of depression, evoked by damage (and loss) appraisals. Negative emotions, in association with active arousal, correspond to emotional/affective states of fear, and, with greater intensity, to anxiety states, evoked by threat appraisals. Positive emotions, in association with passive arousal, correspond to emotional/affective states of calm. Positive emotions, in association with active arousal, correspond to emotional/affective states of joy, and, with greater intensity, to excitement states. Anxiety disorders have repeatedly been associated with an increase in right prefrontal cortex and amygdala activity, abnormalities similar to those reported in depressed subjects [6]. Neuro-stimulation, in particular, high frequency (above $1 \mathrm{~Hz}$ ) repetitive transcranial magnetic stimulation (rTMS) over left dorso-lateral prefrontal cortex treats depressive states [7]. Cohen et al. (1997) [8] have distinguished three perspectives to assess the role of stress in the risk for disease (environmental, biological and psychological perspectives). The environmental perspective focuses on the assessment of environmental events or experiences that are normatively (objectively) associated with substantial adaptation requirements. The biological perspective focuses on the activation of physiological systems, sympathetic-adrenal medullar system and hypothalamic-pituitary-adrenal axis, that are particularly sensitive to physical and psychological demands, and whose prolonged or repeated activation can put people at risk for the development of a variety of physical and psychiatric disorders. The psychological perspective on stress puts emphasis on the perception and evaluation of the potential threat posed by objective environmental experiences. When the demands of involvement are perceived as exceeding the competencies and strategies to cope with the situation, the individual is considered under stress and simultaneously experiences a negative emotional response. Psychological models of stress argue that the events only affect people who appraise them as stressful (perceived stress). Stress appraisals are determined, not only by the stimulus condition or the response variables but, by the person's interpretations of their relations with his/her involvement, that is, the perception of stress is a product of the meaning's interpretation of an event and the evaluation of the adequacy of personal coping resources. The primary appraisal depends on two classes of antecedent conditions: the perceived characteristics of the stimulus situation and the psychological structure of the individual. Some factors affecting primary appraisal of the stimulus situation include the potentiality of damaging confrontation, as well as the magnitude, intensity, duration and controllability of the stimulus. Individual factors affecting primary appraisal include beliefs about oneself and the involvement, the pattern and intensity of personal values and commitments, as well as personality dispositions [8] [9]. Cohen et al. (1997) [8] proposed a unifying model of environmental, psychological and biological perspectives on stress. When confronted with the environmental demands, the person appraises whether they represent a potential threat and if he/she has available skills to adaptively cope with those. Appraising coping resources as insufficient, one will realize his/her situation as stressful, and this stress evaluation results in negative emotional states. When very intense, these same states can directly contribute to the triggering of affective psychiatric disorders, and trigger behavioral or physiological responses that put a person at risk for physical and/or psychiatric disease/s. The model also provides for the possibility that environmental requirements may put the person at risk for disease, even when the evaluation does not result in stress perception nor negative emotional responses. In this model, they are identified two feedback loops, regarding the possibility that an affective state, associated with negative emotions (e.g., depression),can vies stress measurements, as well as the possibility of attribution of physiological activation to a stressor agent, when in fact this is determined by physical exercise or the action of toxic psychoactive substances. Thus, the perception of stress may influence the pathogenesis of physical illness, determining negative emotional states which directly affect physiological processes influencing behavior patterns or risk for disease [8].

\subsection{Executive Function and Its Evaluation through Stroop and Berg Tasks}

Executive function is a multifaceted neuropsychological construct that can be defined as forming, maintaining and shifting of mental sets, corresponding to the abilities to reason and generate goals and plans, maintain focus and motivation to follow through with goals and plans, and flexibly to alter goals and plans in response to changing contingencies. Set formation (i.e., the generation of short- and long-term objectives), through planning and reasoning, with the use of neuro-cognitive processes of focusing attention, generativity, memory retrieval, working memory, sequencing, requires the integrity of dorso-lateral prefrontal cortex, whose injury determines the neuro-behavioral syndrome of disorganization. Set maintenance (i.e., the execution of short- and long-term goals), through follow-through, with the use of neuro-cognitive processes of initiation, response selection (conflict resolution), selective attention, self-monitoring and vigilant attention, requires the integrity of the supe- 
ro-median prefrontal cortex, whose injury determines the neuro-behavioral syndrome of apathy. Set maintenance, through social appropriateness and judgment, with the use of neuro-cognitive processes of inhibition and discrepancy detection, requires the integrity of the ventro-median prefrontal and orbito-frontal cortex, whose injury determines the neuro-behavioral syndrome of desinhibition. Set shifting (i.e., the alteration in short- and long-term goals in response to changes in situations and contexts), through problem solving, with the use of the neuro-cognitive processes of discrepancy detection, cognitive flexibility, attention shifting, generativity, memory retrieval and working memory, requires the integrity of the dorso-lateral prefrontal cortex, whose injury determines the neuro-behavioral syndrome of perseverance. The experimental tasks used to test executive function can be divided into three main categories: cognitive control, working memory and emotional decision. Berg (Wisconsin sorting card test) and Stroop tasks evaluate cognitive control. Stroop tasks evaluate functions involved in set maintenance. Berg task evaluates functions involved in set formation and set shifting (cognitive flexibility). Tower of Hanoi/tower of London tasks evaluate working memory. Iowa gambling task requires participants to consider before a specific purpose, the relative contributions of rewards and punishments, and evaluates emotional decision [10]. Stroop tasks, which computerized version in Psycho Experiment Building Language (PEBL) is victoria Stroop task/test (VST), share the need to select cognitively one of several possible responses to a given stimulus (resolution of conflict/discrepancy), involving, among other functions, inhibition of a pre-potent response, and recruiting visuo-spatial executive components of language and processing speed [11]. Normal performance on Stroop tasks depends mainly on structural and functional integrity of dorso-lateral prefrontal cortex and anterior cingulate cortex [12]-[14]. There is an increase in Stroop interference effect in many psychopathological and neuro-psychiatric disorders, such as dementia and other neurodegenerative disorders (schizophrenia), attention deficit and depression [15]-[17]. Berg task (Wisconsin card sorting test), which computerized version is PEBL's Berg card sorting test (BCST) tests cognitive flexibility [10]. This task is used in the evaluation of patients with brain injury, neurodegenerative disease (including schizophrenia) and depression. Cognitive flexibility, i.e., the mental ability to switch between thinking about two different concepts and think about several concepts at once, is a vital component of learning. Various cognitive components that functionally implement cognitive flexibility, such as recognition of the incorrectness of the environmental feedback stimulus, selection of new dimension through abstract thinking, i.e., conceptual ability, learning how to learn (learning to learn/LTL), inner speech, response inhibition and updating working memory depend on structural and functional integrity of the infero-lateral prefrontal cortex (sub-region of dorso-lateral prefrontal cortex) and caudate nucleus [18] [19].

\subsection{Economic Insufficiency (Poverty, Material Deprivation) and Unemployment}

Poverty determines lack of opportunities, reduced accessibility to resources and a greater likelihood of life events with traumatogenic potential. By acting through stressors agents of socio-economic nature, such as the unemployment and the difficulty of access to housing, it is much more likely that poverty precede mental disorders, such as anxiety and depression, being an important risk factor for mental illnesss [20]. The relationship between poverty and mental illness is bidirectional, that is, poverty is a risk factor for certain mental illnesses, which, in turn, worsen the economic condition of the patient and their families. Some factors, such as education and employment, has a two-way relationship with poverty. The lack of employment results in financial difficulties, and poverty results in reduced opportunity to obtain gainful employment. Unemployed people and those who fail to obtain employment have more depressive symptoms than individuals who can get a job [21]. Limited resources resulting in reduced opportunity for education, which prevent access to most skilled jobs, increase individual vulnerability and insecurity and contribute to a persistently low social capital. The prevalence of common mental disorders is higher among individuals with low levels of education. Chronic poverty is often associated with low levels of family and community support, alcoholism, community insecurity and violent crime, family abuse and family desertion, particularly by men [20]. People in poverty reported higher levels of hopelessness, fatalism, lack of control over their circumstances, as well as a sense of life more oriented to the present than to the future and lower levels of life satisfaction and quality of life, aspects that perpetuate poverty, making it difficult to effectively change the socio-economic status of those who are in poverty situation. The personal debt is a particular source of stress. Working in poverty, represented by financial need and restrictive standards of living, correlates negatively with subjective well-being and is associated with increased risk for not meeting basic needs in mental health [22]. The sudden change of socio-economic status of an individual can result in acute and extreme distress, including suicidal ideation and attempts [23]. The chronically poor families do not 
provide a qualified involvement in child growth and development, and these children have worse cognitive performance and more behavioral problems compared to other children [24]. Adolescents in poverty are more prone to abuse alcohol and illegal drugs and to start an active sex life at an earlier age, as well as manifest greater mental health problems and lower levels of school performance [25]. Poverty generates less favorable family environment, with greater vulnerability of the parents to the debilitating effects of life events, as well as a decreased ability of them to provide consistent socio-family support [24] [25]. Poverty and material deprivation are associated, independently, to the risk for mental disorders in women, to add to the sources of stress usually related to women condition [26]. Studies of poverty and mental health have used a variety of indicators of poverty, including low financial income, material deprivation, unemployment and difficulties in obtaining housing. One of the most cited theoretical frameworks on the impact of unemployment on (physical and psychological) health is Jahoda's model of latent deprivation [27] [28]. This author believes that employment is beneficial from a financial point of view. As well, it provides subject's structure, meaningful activities, shared experiences, goals, social contact and opportunities for recognition and status. Morris, Cooke and Shaper (1994) [29] reported that men, who have suffered loss of employment (unemployment or retirement), are associated to twice the risk for early mortality, compared to men who are continuously employed, being this increase due to a variety of causes, including cancer and cardiovascular disease. Voss, Nylen, Floderus, Diderichsen and Terry (2004) [30] found that unemployment in men is associated with an increased risk of suicide and undetermined cause of death. Cohen et al. (2007) [31] found that unemployed individuals had less cytotoxic activity of their natural killer cell, and that their immune and inflammatory function recovered quickly when they returned to be employed. Janicki-Deverts, Cohen, Matthews and Cullen (2008) [32] found that an unemployment history is associated with increased C-reactive protein levels, an inflammatory marker of early expression in the evolution of cardiovascular disease. Lindstrom (2005) [33] and Brown et al. (2003) [34] also reported increased risk for psychological distress in unemployed people. Maier et al. (2006) [35] studied the impact of unemployment, over time, on the capacity for physical work. Unemployment is associated with a decrease in opportunities for physical activity and with increased psychological/distress suffering. Chronic stress is the main pathway through which unemployment exerts its negative impact on health.

\subsection{Quality of Life and Resilience}

The working group of world health organization on quality of life [36] defined quality of life as "the individual's perception of his/her position in life, in the context of culture and values system in which he/she lives, and in relation to his/her objectives, expectations, standards and concerns". The recognition of the multidimensional nature of the construct is reflected in the structure of the evaluation instruments, including the brief version of the scale of quality of life (WHOQOL BREF), based on physical, psychological, social and environmental domains. Wagnild (2010) [37] shown that resilience protects against negative emotions and thus has the potential to reduce its pathophysiological effects. The resilience scale she proposed, resilience state scale [38] [39], includes four factors: perseverance; meaningful life (purpose); equanimity; existential aloneness (coming home to oneself) and self-reliance. Perseverance refers to the enthusiastic persistence in finding solutions to problems, overcoming adversity, and the will to continue to rebuild life, with an attitude of self-confidence. The meaning of life refers to the awareness that one has something meaningful to live, to the notion that life has a meaning (a reason) in which the individual focuses, avoiding being obsessed with disputes that can't be solved, involving determination and satisfaction with the achievement of defined goals. Equanimity depends on a balanced and focused perspective on the purposes of life, with the capacity to accept the variety of experiences (even adverse) calmly and enthusiastically and the ability to exercise self-esteem. Existential aloneness and self-reliance refer to the awareness that each person's life path is unique and faced in solitude, getting the person confident on his/her ability to depend essentially in him/herself.

\section{Empirical Study}

\subsection{Methods}

This research focused on the impact of unemployment and/or economic insufficiency/poverty (material deprivation) on quality of life, as defined by world health organization. Participants in this study gave written informed, free consent. This study has been developed in concordance with the principles contained in Helsinki Declaration. It is a descriptive, quantitative, correlational, not experimental study. It has been used Pearson correlation 
coefficient $r$. It has been used a convenience sample. Dependent variables comprise the dimensions relating to coping, resilience, quality of life and executive function. Independent variables respect stress associated with situations of unemployment and/or economic insufficiency/poverty (material deprivation). The psychometric scales have been validated for the Portuguese population, and executive function has been evaluated through computerized Stroop and Berg tasks.

\subsection{Participants}

The sample consists of 41 participants, residents in the Portuguese city of Olhão, and $61 \%$ are female. The age presents a mean value of 37.2 years, with a dispersion of values of $25 \%$. As for the time of unemployment, $34 \%$ of the participants were employed less than 2 years, 22\% between 2 and 5 years, $20 \%$ between 5 and 10 years and $24 \%$ over 10 years. In the sample, $10 \%$ of the participants have been unemployed for three months, $20 \%$ for 6 months, 35\% for one year, 32\% for over two years and one participant was always unemployed. As for the annual financial income, $61 \%$ of participants are from the income tax level (AT/IRS) [40] of 11.5\% (i.e., have annual income below 4898 euros), $12 \%$ are ranking at level 14.0\% (i.e., have annual income between 4898 and 7410 euros) and $27 \%$ are in the level of $24.5 \%$ (that is, have annual incomes between 7410 and 18,375 euros). In the sample, $51 \%$ of the participants live accompanied, and $59 \%$ have dependent children (financially in charge). As for the monthly financial income, $24 \%$ of respondents say they do not have an individual income higher than 421 euros, 32\% are currently receiving unemployment benefits. In this study, $98 \%$ of respondents say that, with unemployment, their financial situation has worsened, and 95\% say they live in a country of risk (for poverty).As for scholarship, 98\% of participants have basic or mean (not superior) academic formation. As for health habits, $81 \%$ of the respondents claim that their daily diet is balanced in proteins, sugars, fats, vitamins, minerals (including salt) and water, 27\% regularly practice exercise, 34\% consume drinks containing alcohol, and 51\% drink coffee and/or smoke tobacco (nicotine). In this study, 15\% of participants suffer from chronic physical diseases.

\subsection{Material}

\subsubsection{Coping}

Coping scale brief COPE [41] [42] is a dichotomous scale with two possible answers (from "0" to " 1 ") between "no" and "yes." It consists of 28 items, which are organized into 14 dimensions: active coping (dimension 1); planning (dimension 2); use of instrumental support (dimension 3); use of social emotional support (dimension 4); religion (dimension 5); positive reinterpretation (dimension 6); self-blame (dimension 7); acceptance (dimension 8); expression of feelings (dimension 9); denial (dimension 10); self-distraction (dimension 11); behavioral divestment (dimension 12); use of substances (dimension 13); humor (dimension 14). For each of the dimensions, the values were determined by calculating the sum of the items that constitute them. The minimum possible value is 0 and the maximum possible value is 28 , and for each dimension, the minimum value is 0 and the maximum value is 2 .

\subsubsection{Resilient Coping}

Brief resilient coping scale [43] [44] is an ordinal Likert scale with five possible answers (“1" to " 5 ”) between "almost never" and "almost always." It consists of four items, which are organized in a single dimension. Their values were determined by calculating the sum of the items that constitute them. The minimum possible value is 4 and the maximum possible value is 20 .

\subsubsection{Resilience}

Resilience state scale [38] [39] is an ordinal Likert scale with seven response alternatives ("1" to "7") between "totally disagree" and "totally agree". It consists of 23 items, which are organized in a single dimension. Their values were determined by calculating the sum of the items that constitute them. The minimum value is 23 and the maximum value is 161 .

\subsubsection{Perceived Stress}

Perceived stress scale [45] [46] is an ordinal Likert scale with five possible answers (" 0 " to "4") between "never" and "often". It consists of 10 items, which are organized in a single dimension, and the scale of the items 4, 5, 7 
and 8 (indicated with R) is recoded conversely, since the formulation is held in the negative. Their values were determined by calculating the sum of the items that constitute them. The minimum value is 0 and the maximum value is 40 .

\subsubsection{Life Experiences Survey}

Life experiences survey [47] [48] is an ordinal Likert scale with seven possible answers ("1" to "7”) between "very negative" and "very positive". It consists of 60 items. Their values were determined by calculating the frequency with which each experience occurs and the frequency of the sample elements who consider it negative and also of those who consider it positive.

\subsubsection{Material Deprivation}

Material deprivation scale [49] is a dichotomous scale with two possible answers (from "0" to " 1 ") between "no" and "yes." It consists of nine items which are organized in a single dimension. Items are: capacity to ensure the immediate payment of an unexpected expense of 421 euros (that is, close to the monthly value of the current poverty line) without resorting to loan (item 1); no ability to pay a week's holiday per year away from home, supporting the cost of accommodation and travel for all household members (item 2); delay, motivated by economic difficulties, in some of the regular payments for rent, current credit, benefits or costs of primary residence, or other expenses not related to the principal residence (item 3); no financial capacity to have a meal with meat or fish (or vegetarian equivalent) at least each two days (item 4); no financial capacity to keep home adequately warm (item 5); without availability of washing machine due to economic difficulties (item 6); no color television availability due to economic difficulties (item 7); no landline or mobile phone availability due to economic difficulties (item 8); no car availability (light passenger or mixed) due to economic difficulties (item 9). Their values were determined by calculating the sum of the items that constitute them. The minimum value is 0 and the maximum value is 9 .

\subsubsection{Quality of Life}

Short/brief version of the scale of quality of life/WHOQOL BREF [36] [50] is an ordinal Likert scale with five possible answers (" 1 " to "5"). It consists of 26 items, which are organized into a general index and four domains. For items marked with an "R", the scale is recoded in reverse because its formulation is held in the negative. For each dimension, its values were determined by calculating the sum of the items that constitute them. For the general index, the minimum value is 2 and the maximum value is 10; for domain 1 (physical), the minimum possible value is 7 and the maximum possible value is 35; for domain 2 (psychological), the minimum possible value is 6 and the maximum possible value is 30; for domain 3 (social), the minimum possible value is 3 and the maximum possible value is 15; for domain 4 (environmental), the minimum possible value is 8 and the maximum possible value is 40 . The values of the scores obtained for the various domains were then processed on a scale of 0 to 100.

\subsubsection{Victoria Stroop Task}

In victoria Stroop task/VST [51] [52], it have been used the values of the efficiencies of color/dot (C/D) and color/word (C/W).

\subsubsection{Berg Card Sorting Test}

In Berg card sorting test/BCST [53]-[55], it has been used the parameter values of perseverative errors, learning to learn (LTL) and correct answers.

\subsection{Results}

For brief COPE scale, Cronbach's alpha value is 0.851 , and the mean value is 10.8 . The coping strategy that occurs more frequently is active coping, followed by positive reinterpretation and planning. For brief resilient coping scale, Cronbach's alpha value is 0.717 , with a mean value of 13.4 (higher than the midpoint of measurement scale, which is 12) and most of the values are located between 10 and 16. For resilience state scale, Cronbach's alpha value is 0.904 , with a mean value of 129.8 (above the midpoint of measurement scale, which is 92) and most of the values located between 110 and 150. For perceived stress scale, Cronbach's alpha value is 0.854 , 
with a mean value of 18.27 (below the midpoint of the measurement scale, which is 20) and most of the values located between 15 and 25. For life experiences survey, Cronbach's alpha value is 0.929 , and the event considered negative with higher occurrence is "great change in their economic level" (item 19, which corresponds to $56 \%$ ), followed by "change in sleep habits" (item 4, which corresponds to 39\%), "change in employment status" (item 13, which corresponds to 35\%) and "to be fired from job" (item 32, which corresponds to 34\%). The event considered positive with higher occurrence is "great change in the amount and how to occupy leisure time"(item 29, which corresponds to 51\%), followed by "great change in social activities" (item 36, which corresponds to $39 \%$ ) and "great change of proximity of family members" (item 20, which corresponds to 29\%). For material deprivation scale, Cronbach's alpha value is 0.763 , with a mean value of 3.20 (lower than the midpoint of measurement scale, which is 4.50), and most of the values located between 0 and 4 . For quality of life scale (WHOQOL BREF), Cronbach's alpha value is 0.647. For domain 1 (physical), Cronbach's alpha value is 0.823; for domain 2 (psychological), Cronbach's alpha value is 0.749; for domain 3 (social), Cronbach's alpha value is 0.759; for domain 4 (environmental), Cronbach's alpha value is 0.736 . All mean values are higher than the midpoint, although most related with social domain, followed by the physical and psychological domains. Respecting the efficiency of C/D of VST, the mean value is 1.04, with the majority of the values located between 0.50 and 1.25. Respecting the efficiency of C/W of VST, the mean value is 1.31 , with the majority of the values located between 0.75 and 1.75. Perseverative errors of BCST have a mean value of 15.0, with a dispersion of values of $75 \%$ (the distribution of values of perseverative errors mainly takes place between 0 and 15). Correct answers of BCST have a mean value of 71.4, with a dispersion of values of $22 \%$ (the distribution of values of correct responses mainly takes place between 50 and 90). Learning to learn (LTL) of BCST has a mean value of -0.02 , with a dispersion of values of $31.297 \%$ values (the distribution of values of LTL occurs mainly between -5 and 5).The correlation analysis between variables shows that there are statistically significant positive correlations between:the efficiency of C/D of VST and the overall value of brief COPE, $r=0.333$, $p<0.05$; the efficiency of C/D of VST and dimension 1 (active coping) of brief COPE, $r=0.351, p<0.05$; the efficiency of C/W of VST and the overall value of brief COPE, $r=0.355, \mathrm{p}<0.05$; the efficiency of C/W of VST and dimension 1 (active coping) of brief COPE, $r=0.452, \mathrm{p}<0.01$; the efficiency of C/D of VST and domain 3 (social) of WHOQOL BREF, $\mathrm{r}=0.313, \mathrm{p}<0.05$; the life event "to borrow some money" (item 31 of life experiences survey) and the overall value of perceived stress scale, $r=0.692, p=0.013$; the brief resilient coping scale and the domain 2 (psychological) of WHOQOL BREF, $r=0.512$, $p<0.01$; the brief resilient coping scale and the domain 3 (social) of WHOQOL BREF, $r=0.368, p<0.05$; the resilience state scale and the domain 2 (psychological) of WHOQOL BREF, $r=0.677, p<0.01$; the resilience state scale and the domain 3 (social) of WHOQOL BREF, $r=0.375, p<0.05$; the resilience state scale and the domain 4 (environmental) of WHOQOL BREF, $r=$ 0.396, $\mathrm{p}<0.01$. There are statistically significant negative correlations between: LTL of BCST and dimension 7 (self-blame) of brief COPE, $\mathrm{r}=-0.437, \mathrm{p}<0.05$; material deprivation and the general value of WHOQOL BREF, $r=-0.322, p=0.040$; the perceived stress scale and the resilience state scale, $r=-0.539, p<0.01$; the perceived stress scale and brief resilient coping scale, $r=-0.373, p=0.016$.

\subsection{Discussion and Conclusion}

This research focused on the impact of the economic insufficiency (poverty, material deprivation) and unemployment in quality of life, as defined by World Health Organization. As for the annual financial income, $61 \%$ of participants are from the income tax level (AT/IRS) [40] of 11.5\% (i.e., have annual income below 4898 euros), $12 \%$ are ranking at level $14.0 \%$ (i.e., have annual income between 4898 and 7410 euros) and $27 \%$ are in the level of $24.5 \%$ (that is, have annual incomes between 7410 and 18,375 euros). In the sample, $51 \%$ of the participants live accompanied, and 59\% have dependent children (financially in charge). As for the monthly financial income, $24 \%$ of respondents say they do not have an individual income higher than 421 euros, 32\% are currently receiving unemployment benefits. In this study, $98 \%$ of respondents say that, with unemployment, their financial situation has worsened, and 95\% say they live in a country of risk (for poverty). Material deprivation has a mean value of 3.20. There is a negative correlation between material deprivation and quality of life. As for the time of unemployment, 34\% of the participants were employed less than 2 years, 22\% between 2 and 5 years, $20 \%$ between 5 and 10 years and $24 \%$ over 10 years. In the sample, $10 \%$ of the participants have been unemployed for three months, $20 \%$ for 6 months, 35\% for one year, 32\% for over two years and one participant was always unemployed. As for scholarship, $98 \%$ of participants have basic or mean (not superior) academic 
formation. For life experiences survey, Cronbach’s alpha value is 0.929 , and the event considered negative with higher occurrence is "great change in their economic level" (item 19, which corresponds to 56\%), followed by "change in sleep habits" (item 4, which corresponds to 39\%), "change in employment status" (item 13, which corresponds to 35\%) and "to be fired from job" (item 32, which corresponds to 34\%). The event considered positive with higher occurrence is "great change in the amount and how to occupy leisure time" (item 29, which corresponds to 51\%), followed by "great change in social activities" (item 36, which corresponds to 39\%) and "great change of proximity of family members" (item 20, which corresponds to $29 \%$ ). There is a positive correlation between perceived stress and life event "to borrow some money" (item 31 of life experiences survey). By acting through stressors agents of socio-economic nature, such as unemployment and the difficulty of access to housing, it is much more likely that poverty precedes mental disorders such as anxiety and depression, as well as it constitutes an important risk factor for mental illness [20]. The personal debt is a particular source of stress. Working in poverty, represented by financial need and restrictive standards of living, correlates negatively with subjective well-being, and is associated with increased risk for not meeting basic needs in mental health [22]. Poverty and material deprivation are associated, independently, concerning risk of mental disorders in women, to add to the sources of stress usually related to women condition [26]. Some factors, such as education and employment, has a two-way relationship with poverty. The lack of employment results in financial difficulties and poverty results in reduced opportunity to obtain gainful employment. Unemployed people and those who fail to obtain employment have more depressive symptoms than individuals who can get a job [21]. Morris, Cooke and Shaper (1994) [29] reported that the men, who have suffered job loss (due to unemployment or retirement), is associated with a risk two times higher of (early) mortality, compared to men who are (continuously) employed, this increase being due to a variety of causes, including cancer and cardiovascular disease. Voss, Nylen, Floderus, Diderichsen and Terry (2004) [30] found that unemployment in men is associated with an increased risk of suicide and undetermined cause of death. Lindstrom (2005) [33] and Brown et al. (2003) [34] also reported increased risk of psychological distress in unemployed people. The prevalence of common mental disorders is higher among individuals with low levels of education. In this work, it is found negative correlations between: perceived stress and resilience; perceived stress and resilient coping. There are positive correlations between: resilient coping and quality of life; resilience and quality of life. The perception of stress may influence the pathogenesis of physical illness, determining negative emotional states which directly affect physiological processes influencing behavior patterns or risk for disease [8]. Wagnild (2010) [37] has shown that the resilience protects against negative emotions and thus has the potential to reduce their pathophysiological effects. In this study, there are positive correlations between: performance in the Stroop task, which assesses executive function, and quality of life; Stroop task and active coping (dimension 1) of brief COPE. There is a negative correlation between the performance in Berg task, which assesses cognitive flexibility (performance in the parameter "learning to learn/LTL"), and self-blame (dimension 7 of brief COPE). The adequate performance in Stroop tasks depends mainly on structural and functional integrity of the dorso-lateral prefrontal cortex and anterior cingulate gyrus. The dorsolateral prefrontal cortex is the neuro-biological correlate of working memory [12]-[14]. Berg task is a neuropsychological task that evaluates cognitive flexibility [11] [12]. Various cognitive components that functionally implement cognitive flexibility, such as recognition of the incorrectness of the environmental feedback stimulus, selection of new dimension through abstract thinking, i.e., conceptual ability, learning how to learn (learning to learn/LTL), inner speech, response inhibition and updating working memory depend on structural and functional integrity of the infero-lateral prefrontal cortex, sub-region of dorso-lateral prefrontal cortex [17], and caudate nucleus [18] [19]. This work allowed to highlight that quality of life is positively correlated with resilience skills and active coping strategies. This type of coping is supported by a suitable executive function, as demonstrated in this study. Responsible for the use of active coping strategies is an adequate structural and functional integrity of prefrontal cortex, brain region which is a predominant target of the pathophysiological impact of (chronic) stress. Participants who predominantly use not active coping strategies (self-blame) have less adequate performances in Berg task. The use of not active coping strategies is associated with decreased cognitive flexibility, and suggests dysfunction of infero-lateral prefrontal cortex, in this population.

\section{References}

[1] Lazarus, R S. and Folkman, S. (1984) Stress, Appraisal, and Coping. Springer, New York.

[2] Selye, H. (1974) Stress without Distress. J. B. Lippincott, Philadelphia. 
[3] Folkman, S. and Lazarus, RS. (1980) An Analysis of Coping in a Middle Aged Community Sample. Journal of Health and Social Behavior, 21, 219-239. http://dx.doi.org/10.2307/2136617

[4] Smith, C.A. and Lazarus, R.S. (1990) Emotion and Adaptation. In: Pervin, L.A., Ed., Handbook of Personality: Theory and Research, Guilford, New York, 609-637.

[5] Lang, P.J. (1995) The Emotion Probe: Studies of Motivation and Attention. American Psychologist, 50, $372-385$. http://dx.doi.org/10.1037/0003-066X.50.5.372

[6] Drevets, W.C., Bogers, W. and Raichle, M.E. (2002) Functional Anatomical Correlates of Antidepressant Drug Treatment Assessed Using PET Measures of Regional Glucose Metabolism. European Neuropsychopharmacology, 12, 527544. http://dx.doi.org/10.1016/S0924-977X(02)00102-5

[7] George, M.S., Lisanby, S.H. and Sackeim, H.A. (1999) Transcranial Magnetic Stimulation-Applications in Neuropsychiatry. Archives of General Psychiatry, 56, 300-311. http://dx.doi.org/10.1001/archpsyc.56.4.300

[8] Cohen, S., Kessler, R.C. and Underwood Gordon, L. (1997) Measuring Stress: A Guide for Health and Social Scientists. Oxford, New York.

[9] Cohen, S., Evans, G.W., Krantz, D.S. and Stokols, D. (1986) Behavior, Health and Environmental Stress. Plenum Press, New York. http://dx.doi.org/10.1007/978-1-4757-9380-2

[10] Suchy, Y. (2009) Executive Functioning: Overview, Assessment, and Research Issues for non-Neuropsychologists. Annals of Behavioral Medicine, 37, 106-116. http://dx.doi.org/10.1007/s12160-009-9097-4

[11] Golden, C.J. (1978) Stroop Color and Word Test: A Manual for Clinical and Experimental Uses. Skoelting, Chicago.

[12] Fuster, J.N.M. (2000) The Prefrontal Cortex of the Primate: A Synopsis. Psychobiology, 28, 125-131.

[13] Stuss, D.T., Alexander, M.P., Floden, D., et al. (2002) Fractionation and Localization of Distinct Frontal Lobe Processes: Evidence from Focal Lesions in Humans. Oxford University Press, London.

[14] Lezak, M.D., Howieson, D.B. and Loring, D.W. (2004) Neuropsychological Assessment. Oxford University Press, New York.

[15] Pujol, J., Vendrell, P., Deus, J., et al. (2001) The Effect of Medial Frontal and Posterior Parietal Demyelinating Lesions on Stroop Interference. Neuroimage, 13, 68-75. http://dx.doi.org/10.1006/nimg.2000.0662

[16] Bush, G., Frazier, J.A., Rauch, S.L., et al. (1999) Anterior Cingulate Cortex Dysfunction in Attention-Deficit/ Hyperactivity Disorder Revealed by fMRI and the Counting Stroop. Biological Psychiatry, 45, 1542-1552. http://dx.doi.org/10.1016/S0006-3223(99)00083-9

[17] Kaufmann, L., Ischebeck, A., Weiss, E., et al. (2008) An fMRI Study of the Numerical Stroop Task in Individuals with and without Minimal Cognitive Impairment. Cortex, 44, 1248-1255. http://dx.doi.org/10.1016/j.cortex.2007.11.009

[18] Monchi, O., Petrides, M., Petre, V., Worsley, K. and Dagher, A. (2001) Wisconsin Card Sorting Revisited: Distinct Neural Circuits Participating in Different Stages of the Task Identified by Event-Related Functional Magnetic Resonance Imaging. The Journal of Neuroscience, 21, 7733-7741. http://unf-montreal.ca/oury/Site/publications/J_Neurosci_2001.pdf

[19] Frank, M.J., Loughry, B. and O’Reilly, R.C. (2001) Interactions between Frontal Cortex and Basal Ganglia in Working Memory: A Computational Model. Cognitive, Affective, \& Behavioral Neuroscience, 1, 137-160. http://dx.doi.org/10.3758/CABN.1.2.137

[20] Patel, V. and Kleinman, A. (2003) Poverty and Common Mental Disorders in Developing Countries. Bulletin of the World Health Organization, 81, 609-615.

[21] Simon, G.E., Revicki, D., Heiligenstein, J., et al. (2000) Recovery from Depression, Work Productivity, and Health Care Costs among Primary Care Patients. General Hospital Psychiatry, 22, 153-162. http://dx.doi.org/10.1016/S0163-8343(00)00072-4

[22] Vetter, S., Endrass, J., Schweizer, I., et al. (2006) The Effects of Economic Deprivation on Psychological Well-Being among the Working Population of Switzerland. BMC Public Health, 6, 223. http://dx.doi.org/10.1186/1471-2458-6-223

[23] Elder, G.H. and Caspi, A. (1988) Economic Stress in Lives: Developmental Perspectives. Journal of Social Issues, 44, 25-45. http://dx.doi.org/10.1111/j.1540-4560.1988.tb02090.x

[24] National Institute of Child Health and Human Development, NICHD (2006) Duration and Developmental Timing of Poverty and Children's Cognitive and Social Development from Birth through Third Grade. Child Development, 76, 795-810.

[25] Goosby, B.J. (2006) Poverty and Adolescent Mental Health: The Role of Maternal Psychological Resources. Proceedings of the Annual Meetings of the Population Association of America, Los Angeles, 30 March-1 April 2006. http://paa2006.princeton.edu/papers/60518 
[26] Patel, V., Kirkwood, B.R., Pednekar, S., Weiss, H. and Mabey, D. (2006) Risk Factors for Common Mental Disorders in Women Population-Based Longitudinal Study. The British Journal of Psychiatry, 189, 547-555. http://dx.doi.org/10.1192/bjp.bp.106.022558

[27] Ezzy, D. (1993) Unemployment and Mental Health: A Critical Review. Social Science and Medicine, 37, 41-52. http://dx.doi.org/10.1016/0277-9536(93)90316-V

[28] Janlert, U. and Hammarstrom, A. (2009) Which Model Is Best? Explanatory Models of the Relationship between Unemployment and Health. BMC Public Health, 9, 235. http://dx.doi.org/10.1186/1471-2458-9-235

[29] Morris, J.K., Cook, D.G. and Shaper, A.G. (1994) Loss of Employment and Mortality. BMJ, 308, 1135-1139. http://dx.doi.org/10.1136/bmj.308.6937.1135

[30] Voss, M., Nylen, L., Floderus, B., Diderichsen, F. and Terry, P.D. (2004) Unemployment and Early Cause-Specific Mortality: A Study Based on the Swedish Twin Registry. American Journal of Public Health, 94, 2155-2161. http://dx.doi.org/10.2105/AJPH.94.12.2155

[31] Cohen, F., Kemeny, M.E., Zegans, L.S., et al. (2007) Immune Function Declines with Unemployment and Recovers after Stressor Termination. Psychosomatic Medicine, 69, 225-234. http://dx.doi.org/10.1097/PSY.0b013e31803139a6

[32] Janicki-Deverts, D., Cohen, S., Matthews, K.A. and Cullen, M.R. (2008) History of Unemployment Predicts Future Elevations in C-Reactive Protein among Male Participants in the Coronary Artery Risk Development in Young Adults (CARDIA) Study. Annuals of Behavioral Medicine, 36, 176-185. http://dx.doi.org/10.1007/s12160-008-9056-5

[33] Lindstrom, M. (2005) Psychosocial Work Conditions, Unemployment and Selfreported Psychological Health: A Population-Based Study. Occupational Medicine, 55, 568-571. http://dx.doi.org/10.1093/occmed/kqi122

[34] Brown, D.W., Balluz, L.S., Ford, E.S., et al. (2003) Associations between Short- and Long-Term Unemployment and Frequent Mental Distress among a National Sample of Men and Women. Journal of Occupational and Environmental Medicine, 45, 11569-1166. http://dx.doi.org/10.1097/01.jom.0000094994.09655.0f

[35] Maier, R., Egger, A., Barth, A., et al. (2006) Effects of Short- and Long-Term Unemployment on Physical Work Capacity and on Serum Cortisol. International Archives of Occupational and Environmental Health, 79, 193-198. http://dx.doi.org/10.1007/s00420-005-0052-9

[36] WHOQOL Group (1994) The Development of the World Health Organization Quality of Life Assessment Instrument (The WHOQOL). In: Quality of Life Assessment: International Perspectives, Springer Verlag, Berlin, Heidelberg, 4157.

[37] Wagnild, G.M. (2010) Discovering Your Resilience Core. Resiliencescale.com. http://resiliencescale.net/papers.html

[38] Wagnild, G.M. and Young, H.M. (1993) Development and Psychometric Evaluation of the Resilience Scale. Journal of Nursing Measurement, 1, 165-178.

[39] de Carvalho Ng, C.A.F. and Pereira, I.D. (2012) Adaptação da “Theresiliencescale” para a população adulta portuguesa. Psicologia USP, 23, 417-433. http://dx.doi.org/10.1590/S0103-65642012005000008 http://www.revistas.usp.br/psicousp/article/viewFile/42178/45851

[40] Autoridade Tributária e Aduaneira do Ministério das Finanças do Governo de Portugal (AT) (2012) Modelo 3 de Imposto sobre o Rendimento das Pessoas Singulares(IRS).

http://info.portaldasfinancas.gov.pt/NR/rdonlyres/8687C530-4D05-4CB6-ABFA-0697CC4C180F/0/IRS_2012_interne t.pdf

[41] Ribeiro, J.L.P. and Rodrigues, A.P. (2004) Questões acerca do coping: A propósito do estudo de adaptação do Brief Cope. Psicologia, Saúde \& Doenças, 5, 3-15. http://hdl.handle.net/10400.12/1054

[42] Carver, C.S. (1997) You Want to Measure Coping but Your Protocol’s Too Long: Consider the Brief COPE. International Journal of Behavioral Medicine, 4, 92-100. http://dx.doi.org/10.1207/s15327558ijbm0401_6

[43] Ribeiro, J.L. and Morais, R. (2010) Adaptação portuguesa da escala breve de coping resiliente. Psicologia, Saúde \& Doenças, 11, 5-13.

[44] Sinclair, V.G. and Wallston, K.A. (2004) The Development and Psychometric Evaluation of the Brief Resilient Coping Scale. Assessment, 11, 94-101. http://dx.doi.org/10.1177/1073191103258144

[45] Pais Ribeiro, J. and Marques, T. (2009) A avaliação do stresse: A propósito de um estudo de adaptação da escala de percepção de stresse. Psicologia, Saúde \& Doenças, 10, 237-248. http://hdl.handle.net/10400.12/1091

[46] Cohen, S., Kamarck, T. and Mermelstein, R. (1983) A Global Measure of Perceived Stress. Journal of Health and Social Behavior, 24, 385-396. http://www.jstor.org/stable/2136404 http://dx.doi.org/10.2307/2136404

[47] Silva, I., Pais-Ribeiro, J., Cardoso, H. and Ramos, H. (2003) Contributo para a adaptação da Life Experiences Survey 
(LES) à população diabética portuguesa. Revista Portuguesa de Saúde Pública, 21, 49-60.

https://cms.ensp.unl.pt/www.ensp.unl.pt/dispositivos-de-apoio/cdi/cdi/sector-de-publicacoes/revista/2000-2008/pdfs/205-2003.pdf

[48] Sarason, I., Johnson, J. and Siegel, J. (1978) Assessing the Impact of Life Changes: Development of the Life Experiences Survey. Journal of Consulting and Clinical Psychology, 46, 932-946. http://dx.doi.org/10.1037/0022-006x.46.5.932

[49] Instituto Nacional de Estatística (2010) Sobre a pobreza, as desigualdades e a privação material em Portugal (Onpoverty, Inequality, and Material Deprivation in Portugal). INE, Lisboa.

[50] Vaz-Serra, A., Canavarro, M.C. and Simões, M.R. (2006) Estudos psicométricos do instrumento de avaliação da qualidade de vida da Organização Mundial de Saúde (WHOQOL-Bref) para Português de Portugal. Psiquiatria Clínica, 27, 41-49. http://hdl.handle.net/10849/181

[51] Mueller, S. (2010) The Stroop Test (Web Log Post). PEBL Blog. http://peblblog.blogspot.com/2010/05/stroop-test.html

[52] Troyer, A.K., Leach, L. and Strauss, E. (2006) Aging and Response Inhibition: Normative Data for the Victoria Stroop Test. Aging, Neuropsychology \& Cognition, 13, 20-35. http://dx.doi.org/10.1080/138255890968187

[53] Berg, E.A. (1948) A Simple Objective Technique for Measuring Flexibility in Thinking. The Journal of General Psychology, 39, 15-22. http://dx.doi.org/10.1080/00221309.1948.9918159

[54] Piper, B. (2012) Video of the Berg (Wisconsin) Card Sorting Task (Web Log Post). PEBL Blog. http://peblblog.blogspot.pt/2012/07/video-of-berg-wisconsin-card-sorting.html

[55] Fox, C.J., Mueller, S.T., Gray, H.M., Raber, J. and Piper, B.J. (2013) Evaluation of a Short-Form of the Berg Card Sorting Test. PLoS ONE, 8, 1-4. http://dx.doi.org/10.1371/journal.pone.0063885 